\title{
Редкоэлементный состав расплавных включений в минералах из пород мелилитолитовой серии Гулинского плутона
}

\author{
Асавин А.М. ${ }^{1}$, Буйкин А.И. ${ }^{1}$, Серова Л.Д. ${ }^{2}$, Аносова М.О. ${ }^{1}$, Сенин В.Г. ${ }^{1}$ \\ ${ }^{1}$ Институт геохимии и аналитической химии им. В.И. Вернадского PAH, Москва, aalex086@inbox.ru \\ ${ }^{2}$ Московский государственный университет им. М.В. Ломоносова, Москва, serova-larisa@mail.ru
}

Аннотация. Исследованы составы расплавных включений в главных минералах щелочных пород Гулинского плутона - оливиновый нефеленит, мелилитолит, ункомпагрит, якупирангит. Методом LA-ICP-MS получены данные по редкоэлементному составу расплавов в них. Анализ полученных данных позволяет сделать вывод о относительной бедности редкими элементами мелилититовых расплавов по сравнению с нефелинитовыми. Предложена гипотеза, объясняющая подобный рост концентрации редких элементов в нефелинитовых магмах за счет реакции растворения мелилита. Уровень обогащения, получившегося в результате этой реакции, нефелинитового расплава будет определяться уровнем концентрации редкоземельных элементов, $\mathrm{Sr}, \mathrm{Ba}$, и других редких элементов в мелилите.

Ключевые слова: мелилитовые породы, дифференциация щелочных расплавов, редкоземельные элементы.

\section{The concentration of trace elements in melt inclusions in rocks of the melilitolite sequence of the Gulinsky pluton}

\author{
Asavin A.M. ${ }^{1}$, Buikin A.I. ${ }^{1}$, Serova L.D. ${ }^{2}$, Anosova M.O. ${ }^{1}$, Senin V.G. ${ }^{1}$ \\ ${ }^{1}$ Vernadksy Institute of Geochemistry and Analytical Chemistry RAS, Moscow, makhatadzeg36@gmail.com \\ ${ }^{2}$ Lomonosov Moscow State University, Moscow, serova-larisa@mail.ru
}

\begin{abstract}
We studied the compositions of melt inclusions in the main minerals of alkaline rocks of the Gulinsky pluton, i.e., olivine nephelenite, melilitolite, uncompagrite, and yakupirangite. Using the LA-ICP-MS method, we estimated the content of rare elements in homogenized melts. Our analysis of these data shows a significant difference of the abundance trace element in melilitolite and nephelenite melts. The nephelenite melt is richer than the melilitolite melt. We offer a new hypothetic model of the case of this difference. The reason of this we see in the reaction of melting melilite with olivine with crystallization $\mathrm{n}$ pyroxene and nepheline. The result of this reaction limited the level of the concentration of the trace elements in the nephelenitic melts, because the primary stored in melilitites crystals rare earth elements, $\mathrm{Sr}, \mathrm{Ba}$, and other will be added into the nephelenite liquid as result of the melilite melting reaction.

Key words: melilitolite rocks, differentiation of alkaline melts, rare earth elements, Gulinsky pluton.
\end{abstract}

\section{Введение}

Мелилитолитовая магматическая субфаза в Гулинском полифазном плутоне занимает второе место непосредственно после ультраосновной - оливинит-перидотитовой ультраосновной субфазы. Она представлена широкой серией пород мелилит-пироксенового состава. Для мелилитолитовых пород существует ряд исследований по оценке макро состава исходных магм, которые послужили источником всего разнообразия этой серии пород. Однако, распределения редких элементов в первичных расплавах для высоко кальциевых щелочных серий изучены значительно хуже. Получение новых данных по составу подобных магм представляют значительный интерес.

\section{материалы и методы}

Нами были исследованы магматические расплавные включения в первично магматических минералах: пироксенов, шпинелей, мелилитов; из образцов мелилитолитов (обр. ГХ3, ГХ44) и пикрита (обр. 9769). Включения частично раскристаллизованные, однако состав расплавов в них можно оценить с помощью анализа расфокусированным лучом на микрозонде. Кроме того, предварительная гомогенизация включений за счет нагрева до высокой температуры минеральных монофракций минералов проводилась в платиновых ампулах при контролируемой температуре на установке цилиндр-поршень. Нагрев монофракций пироксена проводился до $1200^{\circ} \mathrm{C}$ при давлении 
0.2 ГПа. Эксперименты выполнены в ИЭМ РАН г. Черноголовка. Аналитические исследования были выполнены в ГЕОХИ РАН г. Москва на микрозонде и с помощью метода лазерной абляции (LA-ICP-MS).

\section{Результаты}

Полученные стекла во включениях могут быть с некоторыми допущениями интерпретированы как захваченное вещество первичного расплава, существовавшего при формировании этих пород. Состав включений приводится в таблице 1. В таблице приводятся составы стекловатых включений из пироксенов в мелилитите (обр. ГХ3) и в пироксене из якупирангита (обр. 9774) Гулинского плутона. Кроме того изучены составы включений в оливине из пикрита (обр. 9769).

Таблица 1. Составы включений по данным микрозондового анализа (вес\%).

Table 1. Composition of the inclusions after the microprobe analysis (wt.\%).

\begin{tabular}{|c|c|c|c|c|c|c|c|c|c|c|c|}
\hline $\begin{array}{c}\text { № } \\
\text { анализа }\end{array}$ & $\begin{array}{l}\text { № } \\
\text { обр. }\end{array}$ & $\mathrm{SiO}_{2}$ & $\mathrm{TiO}_{2}$ & $\mathrm{Al}_{2} \mathrm{O}_{3}$ & $\mathrm{FeO}$ & $\mathrm{MgO}$ & $\mathrm{CaO}$ & $\mathrm{Na}_{2} \mathrm{O}$ & $\mathrm{K}_{2} \mathrm{O}$ & Дополнительно & Сумма \\
\hline$\Gamma \times 3$ & \multirow{3}{*}{$\Gamma \mathrm{X} 3$} & 39.18 & 3.739 & 3.834 & 8.536 & 8.949 & 32.022 & 2.396 & 0.291 & $\begin{array}{c}\text { Валовый состав } \\
\text { породы }\end{array}$ & 56.122 \\
\hline ГХ3-Liq & & 36.7 & 0.01 & & 12.34 & 18.39 & 33.96 & 0.04 & 0.01 & Включ. в Mell & 102.31 \\
\hline$\Gamma \times 3$-Liq & & 51.33 & 0.22 & 0.77 & 0.22 & 0.09 & 33.47 & 8.13 & 0.04 & Включ. в Mell & 94.38 \\
\hline 18 & \multirow{8}{*}{9769} & 45.02 & 3.52 & 5.92 & 6.02 & 16.28 & 16.7 & 1.53 & 1.02 & \multirow{8}{*}{ Включ. в $\mathrm{Ol}$} & 96.13 \\
\hline 22 & & 41.11 & 3.88 & 7.74 & 6.47 & 16.92 & 15.03 & 2.23 & 1.04 & & 94.49 \\
\hline 21 & & 40.08 & 6.21 & 9 & 7.57 & 19.45 & 11.57 & 2.22 & 2.29 & & 98.39 \\
\hline 20 & & 39.51 & 3.78 & 10.65 & 4.31 & 20.01 & 9.24 & 3.16 & 2.2 & & 92.86 \\
\hline 19 & & 39.45 & 7.37 & 10.79 & 4.12 & 22.15 & 7.78 & 3.21 & 2.74 & & 97.61 \\
\hline 17 & & 55.64 & 0.42 & 1.07 & 4.17 & 21.79 & 6.87 & 5.72 & 1.89 & & 97.66 \\
\hline 15 & & 56.23 & 0.32 & 0.7 & 3.45 & 22.32 & 6.79 & 5.73 & 1.95 & & 97.56 \\
\hline 16 & & 55.37 & 0.42 & 1.02 & 3.89 & 21.95 & 6.79 & 5.8 & 1.78 & & 97.02 \\
\hline 2 & \multirow{5}{*}{9774} & 48.9 & 0.2 & 5.07 & 2.79 & 25.55 & 4.53 & 3.71 & 7.28 & \multirow{12}{*}{$\begin{array}{c}\text { Стекло } \\
\text { гомогениз.* в } \\
\text { Срх }\end{array}$} & 98.08 \\
\hline 5 & & 48.97 & 0.22 & 5.57 & 2.61 & 25.09 & 3.8 & 3.98 & 6.64 & & 96.89 \\
\hline 6 & & 53.14 & 0.18 & 2.94 & 2.32 & 24.15 & 4.95 & 5.07 & 4.06 & & 96.82 \\
\hline 7 & & 29.61 & 39.49 & 0.19 & 0.91 & 0.01 & 24.75 & 0.09 & & & 95.11 \\
\hline 14 & & 29.81 & 38.42 & 0.2 & 0.7 & 0.02 & 23.51 & 0.1 & 0.06 & & 92.89 \\
\hline 26 & \multirow{7}{*}{ ГХ44 } & 26.86 & 0.12 & 0.7 & 10.1 & 22.55 & 32.71 & 0.05 & & & 93.2 \\
\hline 27 & & 28.43 & 0.13 & 0.68 & 8.68 & 20.44 & 37.5 & 0.03 & & & 96.02 \\
\hline 28 & & 29.15 & 0.15 & 0.73 & 7.48 & 19.17 & 40.86 & 0.03 & & & 97.78 \\
\hline 9 & & 57.63 & 2.5 & 2.13 & 5.97 & 11.35 & 16.82 & 0.66 & 1.21 & & 99.19 \\
\hline 8 & & 67.77 & 2.34 & 4.42 & 4.18 & 3.13 & 6.78 & 0.95 & 2.63 & & 92.71 \\
\hline 10 & & 65.76 & 3.08 & 4.31 & 1.45 & 5.92 & 11.63 & 0.79 & 2.07 & & 95.23 \\
\hline 11 & & 64.8 & 3.2 & 4.48 & 2.01 & 6.31 & 12.19 & 0.43 & 1.63 & & 95.33 \\
\hline $14 a$ & \multirow{3}{*}{9774} & 60.93 & 3.18 & 3.24 & 6.89 & 5.57 & 10.34 & 0.65 & 2.1 & Включ. в Ol Liq & 93.1 \\
\hline 45 & & 30.01 & 0.08 & 5.88 & 31.54 & 24.78 & 0.89 & 0.05 & 0.05 & Многофаз. вкл. & 93.87 \\
\hline 25 & & 54.35 & 5.85 & 4.14 & 8.05 & 3.81 & 12.33 & 0.42 & 1.2 & Включ. в Spl & 90.18 \\
\hline
\end{tabular}

* Гомогенизация при 0.2 Гпа $980^{\circ} \mathrm{C} .{ }^{*}$ Homogenized melts inclusions under $0.2 \mathrm{Gpa}, 980^{\circ} \mathrm{C}$.

Как видно из таблицы, составы сильно различаются даже в пределах одной породы. С одной стороны это можно объяснить длительным ходом эволюции первичного расплава, а с другой - захватом при анализе вещества минерала-хозяина.

На рисунке 1 представлены тренды изменения состава включений и положения точек составов пород мелилитолитовой субфазы Гулинского плутона и других массивов Маймеча-Котуйской 


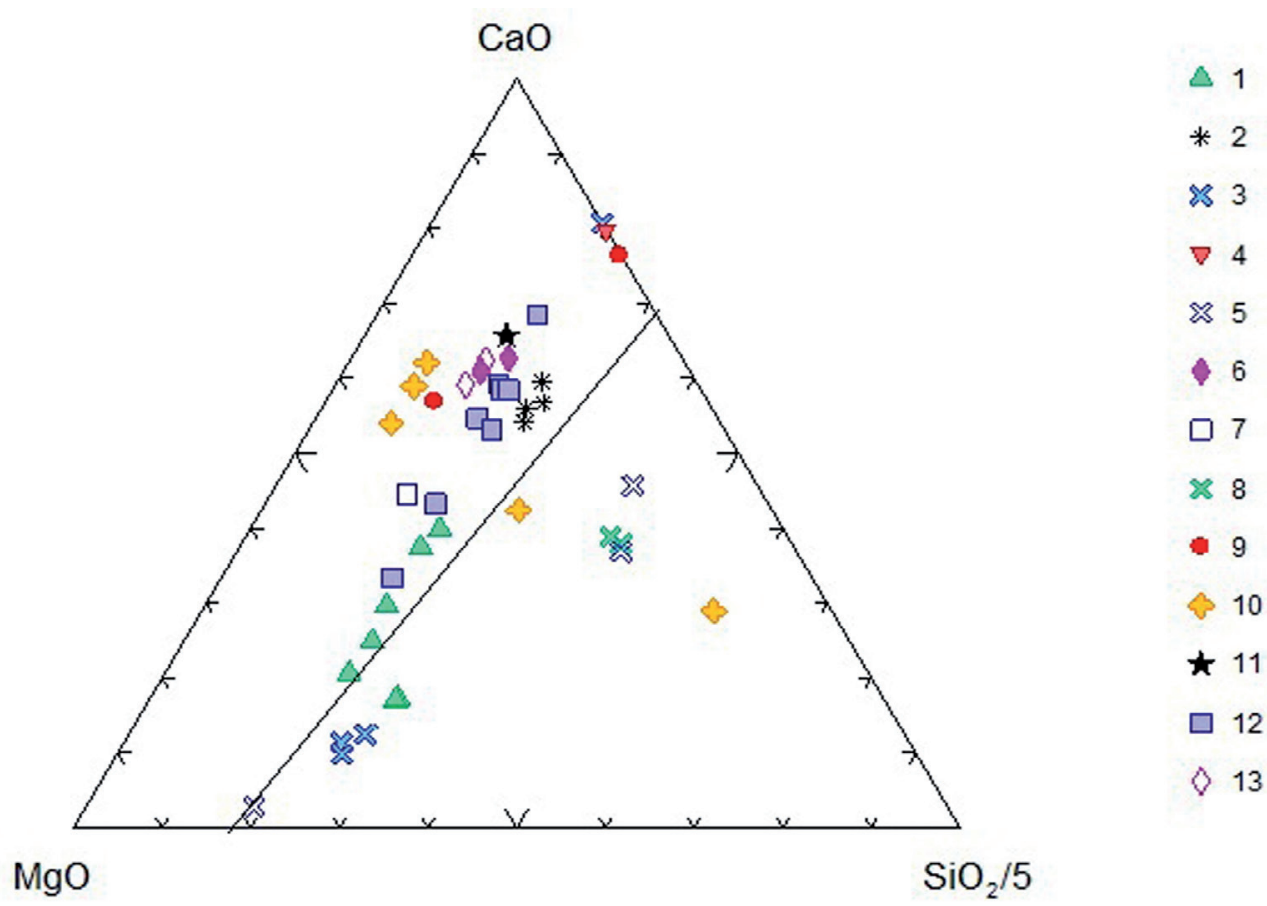

Рис. 1. Составы мелилититовых пород и включений расплава в минералах.

1 - включения в оливине из пикрита $9769 ; 2$ - состав окаитов; 3,4 - гомогенизированные расплавы в якупирангите в Срх; 5 - гомогенизированные расплавы в мелилитолите в Срх; 6 - составы якупирангитов; 7 - составы кугдитов; 8 - гомогенизированные расплавы включений в Срх из ункомпагрита; 9 - гомогенизированные расплавы в Mell из ункомпагрита; 10 - гомогенизированные расплавы включений в Срх из мелилитолита; 11 - валовый состав мелилитолита ГХ $3 ; 12$ - составы турьятов; 13 - составы мелилитолитов. Линия на рисунке разделяет поля ларнит нормативных и нефелинитовых пород.

Fig. 1. Compositions of melilitolite rocks and melt inclusions in minerals.

1 - inclusions in olivine from picrite 9769; 2 - composition of okaites; 3, 4- homogenized melt in Cpx of jacupirangite; 5 - homogenized melts in Cpx of melilitolite; 6 - compositions of jacupirangites; 7 - compositions of kugdite; 8 - homogenized melts inclusions in Cpx of uncompahgrite; 9 - homogenized melts in Mell of uncompahgrite; 10 - homogenized melts of inclusions in Cpx from melilitolite; 11 - bulk composition of melilitolite GX3; 12 - compositions of turjaite; 13 - compositions of melilitolites. A line in the triangle divides fields of the larnite normative rocks and the nephelenite rocks.

провинции (Егоров, 1991). Поля этих пород формируют локальную область и располагаются вблизи угла $\mathrm{CaO}$ треугольника, там же, где располагается точка состава образца мелилитолита ГХ3 (черная звездочка). В этом же районе располагаются желтые точки состава гомогенизированных расплавных включений из мелилититовых пород. Составы включений из якупирангитов и пикрита располагаются значительно ниже и формируют тренды (зеленые треугольники и синие крестики) субпараллельные стороне $\mathrm{MgO}-\mathrm{CaO}$ треугольника.

\section{Обсуждение результатов}

Тренд состава включений в якупирангите и пикрите отличаются тем, что первый идет с небольшим накоплением кремнезема и, вследствие этого, не попадает в область ларнит нормативных составов, а второй тренд расположен субпараллельно стороне $\mathrm{MgO}-\mathrm{CaO}$ треугольника и попадает в область составов мелилитолитовых пород. Составы турьяитов (синие квадраты) и включений в оливиновом нефелините (зеленые треугольники) перекрываются (рис. 1). Тренд точек составов включений из мелилитовых пород располагается еще ближе к стороне $\mathrm{MgO}-\mathrm{CaO}$ треугольника.

На треугольнике (рис. 1) тонкой прямой линией мы нанесли границу двух областей расплавов, эволюция которых дает ларнитнормативные или нефелинитовые составы. Линия начинается от 
точки ларнита $\left(\mathrm{Ca}_{2} \mathrm{SiO}_{4}\right)$ на стороне треугольника $\mathrm{SiO}_{2}-\mathrm{CaO}$ и заканчивается на стороне $\mathrm{MgO}-\mathrm{SiO}_{2}$ на точке состава $\mathrm{Mg}_{2} \mathrm{Si}_{3} \mathrm{O}_{8}$, что в общем составе тетраэдра $\mathrm{Al}, \mathrm{Fe}$, по-видимому, отвечает составу безкальциевого граната $(\mathrm{Fe}, \mathrm{Mg})_{2} \mathrm{Si}_{3} \mathrm{O}_{12}$. Тренды составов расплавных включений из якупирангита приводят к полям мельтейгитов и оливиновых мельтейгитов. Эти породы являются низко магнезиальными (около 10 вес. \% и менее $\mathrm{MgO}$ ) и сходны с составами включений из пироксенов, ийолитов Гулей, проанализированными в работе (Исакова и др., 2015). Как известно, в ларнитнормативной системе существует барьер, обусловленный инконгруэнтным плавлением мелилита (Onuma \& Yagi, 1977) согласно реакции:

$$
\left(\mathrm{Ca}_{2} \mathrm{MgSi}_{2} \mathrm{O}_{7}+\mathrm{CaNaAlSi}_{2} \mathrm{O}_{7}\right)_{\mathrm{Mel}}+\mathrm{Mg}_{2} \mathrm{SiO}_{4 \mathrm{OI}}+\left(\mathrm{NaAiSi}_{3} \mathrm{O}_{8}\right)_{\mathrm{Liq}_{\mathrm{i}}}=3 \mathrm{CaMgSi}_{2} \mathrm{O}_{6}+2 \mathrm{NaAlSiO}_{4}
$$

В результате этой реакции дифференциация ларнитнормативных и нефелинитовых расплавов идет по различным направлениям, и конечные точки псевдоэвтектики у этих расплавов разные. Поэтому важно оценить, какие концентрации редких элементов будут в ларнитнормативных первичных расплавах, поскольку именно от этого будет зависеть степень их рудоносности.
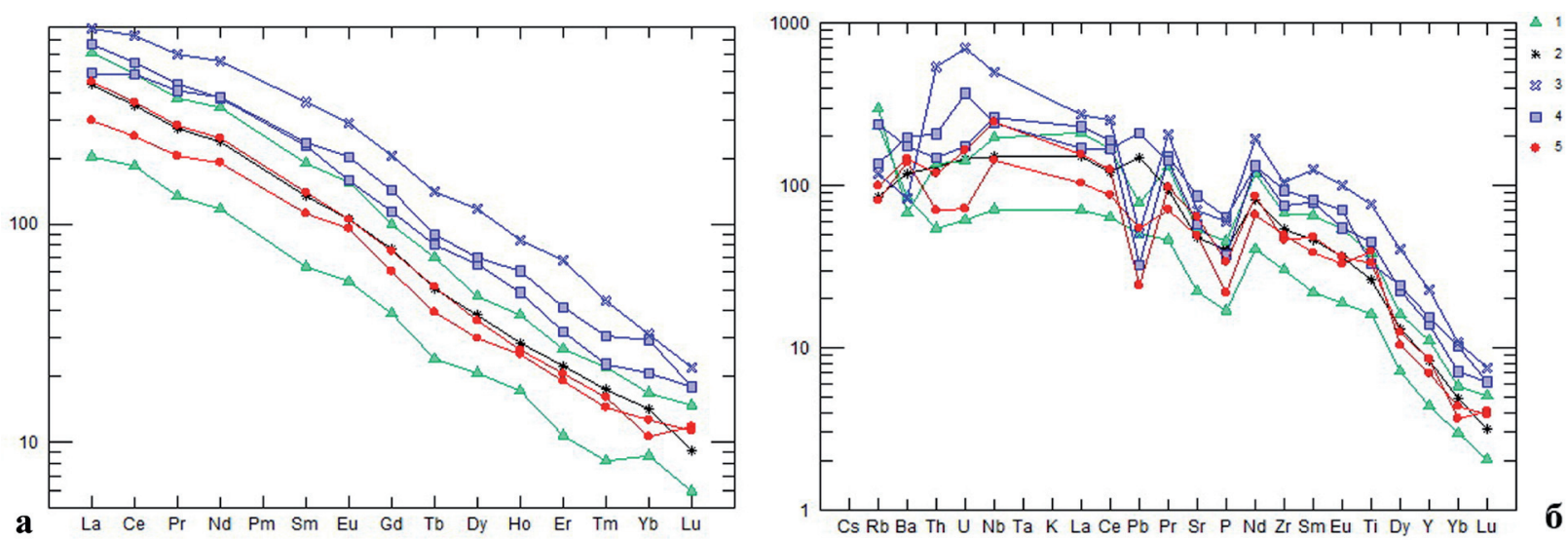

Рис. 2. Составы расплавных включений в пикрите 9769 по данным LA-ICP-MS.

(a) - нормализовано к примитивной мантии, (b) - нормализовано к хондриту (Sun \& McDonough, 1989).

№ анализов: 1 (О1 пикрит) - 02_01,02_01; 2 (Spl пикрит ) - 01_04; 3 (Срх якупирангит) - 06_15; 4-04_08,04_09; 5 (пикрит основная масса) - 1-от, 2-от.

Fig. 2. The compositions of the melt inclusions in picrite 9769 by LA-ICP-MS analysis.

(a) normalized to primitive mantle, (b) normalized to chondrite (Sun \& McDonough, 1989).

№ analyzes: 1 -02_01,02_02; 2-01_4; 3-06_15; 4-04_08, 04_09; 5-1-om, 2-om.

К сожалению, нам не удалось получить данные по содержанию редких элементов в расплавных включениях из якупирангит-мельтейгитовой фазы из-за их мелкого размера. В литературе таких данных тоже нет. Хотя достаточно хорошо охарактеризовано распределение редких элементов в вулканических сериях нефелинитов и мелилитовых нефелинитов - вулканических аналогов рассматриваемых расплавов. В целом, больших различий в составах не обнаружено. Характерные отрицательные пики для $\mathrm{Ba}, \mathrm{P}$ и положительные для $\mathrm{Nb}, \mathrm{Zr}$ в нефелинитовых вулканитах наблюдаются и в мелилитовых нефелинитах. Отсутствие значительной разницы в содержании редких элементов в мелилитовых и нефелинитовых вулканических сериях отмечено и в работах более ранних исследователей (Frey et al., 1978; Sun \& McDonough, 1989). Вторая группа данных относится непосредственно к интрузивным фазам. Ближе к проанализированным нами расплавам, являются модельные составы первичных магм Хибинского массива, которые были использованы в работе (Arzamastsev et al., 2002). По этим данным исходные расплавы пироксен-нефелиновой субфазы почти на 1-2 порядка богаче редкоземельными и литофильными элементами чем мелилититовые. На графиках распределения редких элеменов в мельтейгит-якупирангитах выделяются отрицательные пики для $\mathrm{Pb}$, $\mathrm{Sr}, \mathrm{Zr}$, Ва. Напротив, в мелилититовых расплавах пики $\mathrm{Ba}, \mathrm{Pb}, \mathrm{Sr}, \mathrm{Zr}$ положительные. Модель, раз- 
виваемая Арзамасцевым с соавторами, предполагает, что за счет эволюции единого расплава при кристаллизационной дифференциации можно получить всю серию интрузивных пород в щелочных плутонах. Однако, большая разница (на порядки величин) в содержаниях редких элементов не может быть объяснена простым накоплением редких элементов при фракционировании главных минералов. Возникает вопрос: в результате какого процесса можно получить наблюдаемую разницу в уровне концентраций нефелинитовых и мелилититовых расплавов? И чем обусловлены характерные отрицательные аномалии $\mathrm{Pb}, \mathrm{Ba}, \mathrm{P}, \mathrm{Sr}$ на графиках распределения редких элементов?

В качестве гипотезы, объясняющей наблюдаемое распределение, можно предложить следуюший механизм. На этапе инконгруэнтного плавления мелилита температура и состав расплава стабилизируется, а фракционирование клинопироксена отсутствует. За счет плавления мелилита изоморфные его структуре компоненты - TR, $\mathrm{Sr}, \mathrm{Ba}$, с высокими коэффициентами распределения перераспределяются в расплав, резко обогащая его. Процесс обогащения усиливается и на этапе более позднего фракционирования пироксена. Такими процессами мы можем объяснить относительное обогащение нефелинитовых расплавов редкоземельными элементами $\mathrm{Sr}, \mathrm{Ba}$. Мелилит при этом выступает как источник редких элементов, обогащающий расплав. Участие в реакции мелилита может объяснить появление положительных аномалий $\mathrm{Sr}, \mathrm{Ba}$ в мелилититовых расплавах. Мелилит является в этом отношении уникальной породообразуюшей фазой - хранилищем редких элементов. В зависимости от степени протекания реакции плавления он будет либо обогащать нефелинитовый расплав накопленными редкими компонентами, либо обеднять остаточный расплав ими же за счет физической отсадки мелилита. Причем, следует подчеркнуть, что если рассматривать мелилититы и ункомпагриты как продукт кумулятивной отсадки мелилита и пироксена, то за содержание в этих породах редких элементов будет отвечать именно мелилит, а содержание в нем редкоземельных элементов определит та стадия, на которой он кристаллизовался. На ранней стадии в ассоциации оливин+мелилит концентрация редких элементов скорее всего будет максимальной, а на более поздних стадиях, с началом реакции плавления, будет минимальна.

\section{Выводы}

Мы интерпретируем наличие широкого интервала составов стёкол в микровключениях как результат протекания реакции инконгруэнтного плавления мелилита согласно реакции (Onuma \& Yagi, 1977) с растворением оливина и кристаллизацией клинопироксена. В результате формируется 2 тренда. Первый отвечает ларнитнормативным расплавам и попадает в область составов интрузивных пород мелилитолитовой фазы Гулинского плутона. Второй тренд характеризуется накоплением кремнезема и отвечает эволюции нефелинитовой магмы.

Распределение редких элементов в высококальциевых расплавных включениях, несмотря на широкий интервал концентраций, однотипно. Спектры характеризуются преобладанием легких редкоземельных элементов над тяжелыми, наличием отрицательной аномалии $\mathrm{Ba}, \mathrm{P}, \mathrm{Pb}, \mathrm{Sr}$. Heфелинитовые расплавы характеризуются более высоким уровнем содержания редких и редкоземельных элементов по сравнению с мелилититовой. В спектре также отмечены отрицательные аномалии $\mathrm{Ba}, \mathrm{P}, \mathrm{Pb}$. Кроме того, заметна отрицательная аномалия Zr.

Причиной обогащения нефелинитового расплава редкими элементами относительно ларнитнормативных расплавов может быть выделение в результате плавления мелилита накопленных в нем ранее TR, Sr и других редких элементов, в которых величина коэффициента распределения мелилит-расплава больше 1 .

Работа поддержана из средств грантов РФФИ No.19-05-00681.

\section{Литература}

1. Егоров Л.С. Ийолит-карбонатитовый плутонизм (на примере Маймеча-Котуйского комплекса Полярной Сибири) // Проект МПГК 314. Л.: Недра. 1991. 260 с.

2. Исакова А.Т., Панина Л.И., Рокосова Е.Ю. Карбонатитовые расплавы и генезис апатитового оруденения на. Гулинском плутоне // Геология и геофизика. 2015. Т. 56 (3). С. 595-607. 
3. Arzamastsev A.A., F. Bea, L.V. Arzamastseva, P. Montero. Rare earth elements in rocks and minerals from alkaline plutons of the Kola Peninsula, NW Russia, as indicators of alkaline magma evolution //Russian Journal of Earth Sciences. 2002. V. 4. N. 3. P. 187-209.

4. Frey F.A., Green D.H. \& Roy S. 1978. Integrated models of basalt petrogenesis: a study of quartz tholeiites to olivine melilites from southeastern Australia utilizing geochemical and experimental petrologic data. J PETROL 19. P. 463-513.

5. Onuma K., \& Yagi, K. Differentiation of melilite nephelinitic rocks in light of experimental study of the system $\mathrm{Na}_{2} \mathrm{O}-\mathrm{CaO}-\mathrm{MgO}-\mathrm{Al}_{2} \mathrm{O}_{3}-\mathrm{TiO}_{2}-\mathrm{SiO}_{2} / /$ Journal of the Faculty of Science, Hokkaido University. Series 4, Geology and mineralogy. 1977. V. 17(3). P. 437-449.

6. Sun S.S., \& McDonough W.S. Chemical and isotopic systematics of oceanic basalts: implications for mantle composition and processes // Geological Society, London, Special Publications. 1989. V. 42 (1). P. 313-345. 